\title{
КАК «ДИЛЕММА ЗАКЛЮЧЕННОГО» ОБУСЛАВЛИВАЕТ РЕГУЛЯТИВНУЮ ФУНКЦИЮ ПРАВА?
}

\author{
(c) 2020 Колосов Игорь Владимирович \\ соискатель кафедры истории права и государства Юридического института \\ Российский университет дружбы народов, Россия, Москва \\ E-mail: i.v.kolosov@yandex.ru
}

Настоящая статья посвящена обоснованию при помощи методологии теории игр необходимости регулирования общественных отношений правовыми нормами. Теоретическая значимость статьи связана с тем, что, несмотря на наличие значительного количества англоязычных работ, для российской юридической науки поднимаемый вопрос является относительно новым. Актуальность статьи и ее практическая значимость обуславливается возможностями по выявлению оптимальных решений в рамках правотворчества и правоприменения.

Ключевые слова: Теория игр, дилемма заключенного, игра, исследование операций, регулятивная функция права, Т. Гоббс.

«Дилемма заключенного» представляет собой один из наиболее распространенных“ к применению в юридической науке пример игры, анализируемой теорией игр***, который обосновывает, что в ситуации конкуренции за реализацию собственных интересов два рационально действующих лица не будут сотрудничать, если отсутствует уверенность, что достигнутые договоренности (или неформальные правила) будут исполняться другой стороной, хотя сотрудничество привело бы к наиболее выигрышной ситуации как для «общества» (состоящего из этих двух лиц), так и для каждого из этих лиц в отдельности.

Идентификация существующих в обществе интересов и проецирование их в правовом измерении, как отметила М.В.Немытина, «позволяют увидеть спектр методологических ракурсов, дающий импульс новым направлениям правовых исследований»***. С учетом этого, анализ интересов лиц, вступающих в общественные отношения, методологией теории игр позволит как определить мотивы принятия юридически значимых решений, так и выявить оптимальные механизм правового регулирования и решения при правоприменении.

«Дилемма заключенного» может использоваться в качестве модели для многих реальных ситуаций, связанных с совместным поведением, взаимодействием лиц в рамках общественных отношений, а значит, актуальна для юридической науки. «Дилемма заключенного» может применяться и к ситуациям, не строго соответствующим формальным критериям классических или итеративных (повторных) игр: например, тех, в которых два лица могут получить выгоды от сотрудничества или пострадать от отказа от сотрудничества, но им сложно, затратно или невозможно координировать деятельность друг с другом.

Как было отмечено К.Е.Сигаловым, «игра и соревнование $-[\ldots]$ это основание равнопра-

\footnotetext{
* Так, например, Р.Х. МакАдамс, обосновывает, что частота упоминаний и использования «дилеммы заключенного» в юридических исследованиях довольно высока (McAdams R. H. Beyond the Prisoner's Dilemma: Coordination, Game Theory and the Law. (John M. Olin Program in Law and Economics Working Paper No. 437, 2008). 56 p.).

** «Теория игр - раздел прикладной математики, в котором рассматриваются методы изучения оптимальных стратегий в играх. Под игрой понимается процесс, в котором участвуют две и более сторон, ведущих борьбу за реализацию своих интересов. Каждая из сторон имеет свою цель и использует некоторую стратегию, которая может вести к выигрышу или проигрышу - в зависимости от поведения других игроков» (Максимова Н. Н. Теория игр: учебно-методическое пособие / Н. Н. Максимова.- Благовещенск: Изд-во АмГУ, 2015. С. 3).

*** Немытина М.В.Интересы в правовом измерении. / В сборнике: «Интересы в праве. Жидковские чтения», под общ. ред.д.ю.н., проф. М.В.Немытиной. 2017. С. 6.
} 
вия и свободы»*. Учитывая свободу действий, ограничиваясь запретами, установленными правом (формальным) и неформальными институтами**, для того чтобы победить в игре и соревновании, увеличить собственную выгоду требуются слаженные действия. Вместе с тем лицам, вступающим в общественные отношения, в виду их оппортунистического поведения, как это продемонстрировано в «дилемме заключенного», может быть более выгодно действовать не в кооперации, а в собственных интересах.

Так, согласно «дилемме заключенного» если один правонарушитель свидетельствует против другого, при этом второй не дает показаний против первого, то первый освобождается от ответственности, а второй получает максимальное наказание. Нераскрытие первым информации о правонарушениях второго привело бы к тому, что каждый из правонарушителей получил бы минимальное наказание и это было бы Паретооптимальным распределением между правонарушителями. Раскрытие информации обоими правонарушителями привело бы к более жесткому наказанию для каждого, но к меньшему, чем максимальное, что и достигается в условиях, если заключенные максимизируют собственную полезность. Ситуация, описанная в «дилемме заключенного», в условиях отсутствия права или неформальных правил не приводит к свободе. Обусловить достижение равноправия и свободы в ситуациях, попадающих под структуру «дилеммы заключенного», может право и неформальные правила***.

В классической «дилемме заключенного» подразумевается отсутствие возможности воздействовать на другого заключенного, например, предоставить награду за неразглашение сведений или угрожать за сотрудничество со

\begin{tabular}{|c|c|c|c|}
\hline \multirow{4}{*}{} & $\begin{array}{c}\text { Решение } \\
\text { заключенных }\end{array}$ & $\begin{array}{c}\text { Не свидетельствовать } \\
\text { против заключенного } \\
\text { № } 1\end{array}$ & $\begin{array}{c}\text { Сотрудничать со } \\
\text { следствием }\end{array}$ \\
\hline \multirow{4}{*}{ Заключенный № 1} & $\begin{array}{c}\text { Не свидетельствовать } \\
\text { против заключенного } \\
\text { № } 2\end{array}$ & $(-1 ;-1)$ & $(-10 ; 0)$ \\
\cline { 2 - 4 } & $\begin{array}{c}\text { Сотрудничать со } \\
\text { следствием }\end{array}$ & $(0 ; 10)$ & $(-5 ;-5)$ \\
\hline
\end{tabular}

Рис. Матрица решений «дилеммы заключенного»

\footnotetext{
* Сигалов К.Е.Исторические основания игр, имманентных праву. / В сборнике: «Право - явление цивилизации и культуры», под общ. ред.д.ю.н., проф. М.В.Немытиной. Выпуск І. 2019. С. 45.

** Согласно нормативному подходу институт рассматривается как установленное извне правило, регламентирующее поведение человека. Институт выступает в качестве некоторого внешнего ограничителя свободы выбора человека. Формы регламентации как правило различаются по степени жесткости и по степени формализованности. Формализованность регулирующего правила характеризуется степенью участия властных структур общества в процессе регулирования поведения индивида и его наказания. Институты, обладающие высокой степенью формализованности, называют формальными, а институты, обладающие низкой степенью формализованности,- неформальными (Шавкунова И.С. Ш14 Институты и их роль в жизни общества.: учеб. пособие для студентов, магистрантов / И. С.Шавкунова.- Иркутск: Изд-во БГУЭП, 2015. С. 7). Таким образом, право является формальным институтом.

*** В большей мере данный тезис относится к иным общественным отношениям, проанализированным далее, не связанным с необходимостью координации правонарушителями своих действий для минимизации размера юридической ответственности, и здесь приводится в классической модели «дилемма заключенного» для только целей обоснования использования институтов для достижения Парето-оптимального распределения. Автор данным тезисом не намерен обусловить мысль о нецелесообразности привлечения к юридической ответственности и необходимости обеспечить правонарушителям при помощи права уверенность в том, что другой правонарушитель не будет сотрудничать со следствием. Наоборот, гарантированность или высокая вероятность привлечения к юридической ответственности является одним из способов упорядочить общественные отношения таким образом, чтобы стремление к достижению собственных интересов, в том числе в рамках ситуаций, анализируемых «дилеммой заключенного», не приводило к ущемлению интересов других лиц.
} 
следствием. Единственными результатами для заключенных в стандартной игре «дилемма заключенного» являются приговоры к тюремному заключению, которые они получают и на которые они могут повлиять, принимая решение сотрудничать со следствием или не раскрывать информацию о преступлениях другого заключенного. Поскольку первое из указанных действий влечет сравнительно большие выгоды при любом из решений другого заключенного*, рационально действующие заключенные будут сотрудничать со следствием, даже, несмотря на то, что нераскрытие информации каждым из заключенных привело бы к существенно меньшим срокам.

Парето-оптимальное распределение между правонарушителями не достигается, поскольку единственное возможное равновесие - раскрытие информации каждым из заключенных в отношении правонарушений другого. Каким бы не было поведение другого правонарушителя, будет более выигрышная стратегия по «сдаче» второго.

Формальные и неформальные институты могут повлиять на принимаемые в таких ситуациях решения. Например, если оба заключенных состоят в организованной преступной группе, то правило о недопустимости «сдачи» другого заключенного, поддерживаемое авторитетом руководителей такой преступной группы, находящихся на свободе (и угрозой наказания со стороны такой группы) (далее - институты преступного сообщества), может существенным образом повлиять на принятие заключенными решений и привести к Парето-оптимальному распределению между правонарушителями каждый не «сдаст» другого и получит при этом минимальный срок.

Иное следствие «дилеммы заключенного» выражается в том, что возможны ситуации, когда в интересах обоих заключенных сознаться в преступлении и свидетельствовать против другого, даже в случае невиновности обоих. Наиболее худшей ситуацией является вариант, когда среди двух заключенных только один виновен в совершении преступления. В данном случае оптимальной стратегией для преступника будет свидетельствование против невиновного, в то время как последний вероятно не сознается в преступлении, которого он не совершал. Таким образом, возможна ситуация с освобождением преступника и осуждением невиновного.

Государственная политика по борьбе с преступностью и соответствующее этому нормативно-правовое регулирование должно учитывать эти следствия из «дилеммы заключенного», во-первых, путем предоставления, при необходимости, возможностей по государственной защите лиц, сотрудничающих со следствием, в случае если предоставляемая ими информация является ценной для поимки иных правонарушителей, привлечения их к юридической ответственности и предотвращения преступлений а, во-вторых, путем обеспечения всесторонней проверки информации сотрудничающих со следствием заключенных. Необходимо с осторожностью относится к сделкам о признании вины, когда в случае признания заключенным вины в совершении преступления, дальнейшее следствие не проводится или проводится в недостаточном для выявления истины объеме. Во взаимосвязи с последним необходимо учитывать, что в ситуации со сделкой со следствием возможно укрывательство невиновным лицом действительного преступника, например, когда ожидаемое наказание в рамках институтов преступного сообщества оценивается заключенным выше, чем наказание в рамках формальных институтов, то есть предусмотренное уголовным законом.

Многие социальные взаимодействия демонстрируют структуру «дилеммы заключенного». Именно в них более наглядно проявляется уже упомянутая формула по обеспечению в условиях соревнований и игр равенства и свободы при помощи права. Например, в рамках простого экономического обмена, поскольку зачастую оплата и поставка товара не одномоментные (или могут иметь место скрытые свойства товара, иная асимметрия информации), появляется гипотетическая возможность неисполнения надлежащим образом обязательств по договору (не платить, не поставлять товар или поставить товар ненадлежащего качества). Если продавец поставит товар надлежащего качества, а покупатель его оплатит, то достигается Паретооптимальное распределение между сторонами договора. Но в условиях отсутствия права и неформальных правил, каждому из контрагентов может быть более выгодным в рамках конкрет-

\footnotetext{
* «0» против «-1» (в случае если другой правонарушитель не раскрывает информацию о правонарушениях первого) и «-5» против «-10» (в случае если другой правонарушитель сотрудничает со следствием).
} 
ной сделки нарушение обязательств, продавцу - сохранить товар за собой, получив при этом оплату, или поставить товар ненадлежащего качества при получении оплаты в полном объеме; покупателю - безвозмездно получить товар. Осуществление такого оппортунистического поведения максимизирует полезность недобросовестного участника гражданского оборота, поскольку в условиях отсутствия гарантированного правом встречного исполнения контрагентом обязательств (например, институтом привлечения к гражданско-правовой ответственности за неисполнение или ненадлежащее исполнение обязательств), будут иметь место сравнительно большие выгоды (или исключены потери) при любом из возможных поведений контрагента.

Частично проблема решается в случае, если игра является итеративной (повторной)* - покупатель и продавец с меньшей вероятностью пойдут на обман, рассчитывая на добросовестные взаимоотношения в дальнейшем. Тем не менее, и в этой ситуации могут быть проявления оппортунизма, в особенности, если для выявления скрытых дефектов товара требуется определенное время или специальные знания, проведение экспертиз ${ }^{* *}$. Именно право как регулятор общественных отношений путем установления ответственности за неисполнение или ненадлежащее исполнение обязательств, а также способов обеспечения исполнения обязательств, относительно эффективно может пресекать оппортунистическое поведение контрагента по договору, поскольку правом должно обеспечиваться соблюдение условий договора не только в рамках итеративных игр, но даже в ситуации классической (неповторяющейся) игры.

Известная в экономической теории пробле- ма «безбилетника» - ситуации, при которой экономические субъекты бесплатно пользуются общественными благами (в виду их неисключаемости), функционирование которых, тем не менее, требует определенных расходов, является примером «дилеммы заключенного» с множеством участвующих в соответствующих общественных отношениях лиц. Автобусные системы города Москвы, а также во многих европейских странах устроены по принципу отсутствия в транспортном средстве лица, уполномоченного осуществлять контроль оплаты проезда. В целом такие системы основываются на доверии. Тем не менее, они могут работать только в том случае, если достаточное количество пассажиров оплачивает проезд. С экономической точки зрения, наилучший результат для каждого пассажира в отдельности - это не платить за проезд, в то время как другие бы платили, чтобы автобусная система могла функционировать. Но если все примут эту стратегию, автобусы перестанут ходить, и всем придется использовать альтернативный вид транспорта, что будет проигрышем для всех.

Любой вид общественного блага сталкивается с этой проблемой. Она характера для загрязнения окружающей среды или национальной обороны. Еще один пример связан с разоружением отдельных государств и мирового сообщества в целом. Государства находятся перед дилеммой - увеличить ли расходы на вооружение или направить высвободившиеся средства на социальное обеспечение, продовольствие и иные нужды (проблема «пушки вместо масла»). С политической точки зрения, лучшая ситуация для государства - это иметь достаточное количество вооружения, в то время как все другие

\footnotetext{
* В том числе за счет того, что такая стратегия участников экономического оборота влечет невозможность участников гражданского оборота осуществлять экономический обмен и заключать иные договоры, имеющие консенсуальный характер.

** С учетом проведенного Дж. Акерлофом анализа рынка «лимонов» (Akerlof G.A.The Market for «Lemons»: Quality Uncertainty and the Market Mechanism. In: Estrin S., Marin A. (eds) Essential Readings in Economics. Palgrave, London. 1995. Р. 175-188), оппортунистическое поведение со стороны продавца в итеративных играх на практике приводит к Парето-неоптимальному результату, в частности на рынках с высокой асимметрией информации, например, на рынке поддержанных автомобилей. Продавцы «слив» («хороших автомобилей» в понимании Дж. Акерлофа) вынуждены либо отказаться от продажи, либо продавать автомобиль по цене, соответствующей стоимости «лимона» («плохих автомобилей» в понимании Дж. Акерлофа), покупатели же вынуждены с большей вероятностью покупать «лимоны» в виду ухода с рынка «слив». «Щлохие» машины имеют тенденцию вытеснять с рынка «хорошие» (во многом подобно тому, как «плохие» деньги согласно закону Грешема вытесняют «хорошие»)» (Ibid, p. 176-177). Это обусловлено более выигрышной стратегией игры в рамках «дилеммы заключенного» - покупатели не готовы приобретать автомобиль по более высокой цене, поскольку в условиях асимметрии информации не могут отличить «сливу» от «лимона» и рискуют купить «лимон» по цене «сливы», что невыгодно, а продавцы «слив» в такой ситуации снижают цену до невыгодной для себя или уходят с рынка.
} 
государства будут разоружаться. Поскольку все же лучше быть вооруженным, если другие нации вооружены, это делает вооружение доминирующей стратегией, которая дает знакомый из «дилеммы заключенного» результат: вооруженные страны получают худший результат, чем если бы все разоружились, но это более оптимальная стратегия, чем если бы конкретная страна разоружилась, а другие нет. В некоторой степени решению данной проблемы могут способствовать международные договоры.

Во всех вышеуказанных и в иных ситуациях, для которых актуальна «дилемма заключенного», наиболее действенным способом получить уверенность в том, что возможно доверять лицу, вступающему в игру, в том, что оно выполнит свою часть обязательств в игре, является создание механизма, гарантирующего применение санкций к тем, кто играет не правилам.

Томас Гоббс считал, что единственный выход из социальных ситуаций, подобных указанным,- это иметь какой-то механизм, который гарантировал бы, что люди не будут в собственных интересах отступать от ранее принятых договоренностей, будут исполнять принятые на себя обязательства, иметь какой-то способ обеспечить соблюдение соглашений или контрактов, налагая санкции на тех, кто нарушает их. Для Т. Гоббса государство было органом принуждения - «соглашения без меча лишь слова, которые не в силах гарантировать человеку безопасность»*. Без существования законов, правительства, судов и иных правоохранительных органов все были бы в «естественном состоянии», по сути, структурированном как «дилемма заключенного» (до момента вмешательства права и неформальных институтов), постоянном состоянии «войны всех против всех». Отсюда, согласно его бессмертным словам, государство необходимо, чтобы уберечь людей от одиночества, бедности, беспросветности, тупости и кратковременности ${ }^{* *}$.

Юридическая ответственность, налагаемая на тех, кто укрывает доходы в целях меньшей уплаты налогов, или тех, кто пойман на бесплатном проезде в общественном транспорте, являются типичным примерами сдерживания «мечом» от совершения правонарушений, от оппортунистического поведения, направленного на извлечение собственной выгоды в ущерб третьим лицам. Таким образом, необходимость избежать оппортунизма в рамках «дилеммы заключенного» является аргументом в пользу создания сильного государства, гарантирующего исполнение принимаемых на себя экономическими субъектами обязательств, во благо всего общества.

Как результат соответствующей государственной политики и правового регулирования экономические субъекты, вступающие в игру, в рамках «дилеммы заключенного» более вероятно будут принимать решения, максимизирующие общественную полезность, поскольку будут защищены от оппортунистического поведения контрагента правовыми нормами, обязательность которых будет гарантироваться силой государственного принуждения. Сотрудничество уже на ранних этапах серии игр по модели «дилемма заключенного» делает возможным Парето-оптимальное распределение не только в классической ситуации, но и увеличивает выгоды при повторных играх, связанные со снижением неопределенности, по причине изначальной относительной уверенности в надежности контрагента и меньшими затратами, связанными с необходимостью проверять надежность контрагента на следующих итерациях.

\section{Библиографический список}

1. Гоббс, Т. Соч.: в 2 т. М., 1989-1991. Т. 2. М.: Мысль - 731 с.

2. Максимова, Н.Н. Теория игр: учебно-методическое пособие / Н. Н. Максимова.- Благовещенск: Изд-во АмГУ, 2015.- 94 с.

3. Немытина, М.В. Интересы в правовом измерении. / В сборнике: «Интересы в праве. Жидковские чтения», под общ. ред.д.ю.н., проф. М.В.Немытиной. 2017. С. 5-13.

4. Сигалов, К.Е. Исторические основания игр, имманентных праву. / В сборнике: «Право - явление цивилизации и культуры», под общ. ред.д.ю.н., проф. М.В.Немытиной. Выпуск I. 2019. С. 45-52.

5. Шавкунова, И.С. Институты и их роль в жизни общества: учеб. пособие для студентов, магистрантов / И. С. Шавкунова. - Иркутск: Изд-во БГУЭП, 2015.- 72 с.

\footnotetext{
* Гоббс Т. Соч.: в 2 т. М., 1989-1991. Т. 2. С. 129.

** Там же, с. 96.
} 
6. Akerlof, G.A. The Market for «Lemons»: Quality Uncertainty and the Market Mechanism. In: Estrin S., Marin A. (eds) Essential Readings in Economics. 1995. Palgrave, London. P. 175-188.

7. McAdams, R.H. Beyond the Prisoner's Dilemma: Coordination, Game Theory and the Law. (John M. Olin Program in Law and Economics Working Paper No. 437, 2008).- 56 p. 